\title{
COMMUNICATIONS
}

\section{DEFECTIVE VISION IN WEST INDIAN IMMIGRANTS*†}

\author{
BY \\ R. A. OWEN \\ From King's College Hospital, London
}

DURING the last 10 years there has been a more than 10 -fold increase in the population of West Indians living in south-east London. This influx has introduced certain diseases and conditions which have not been seen previously in the local white population. In particular, a number of West Indians with defective vision have presented themselves at King's College Hospital for examination.

Initially there has been no obvious cause for their visual defect, and no specific history of disease or ill-health. The degree of defect in visual acuity has been approximately equal in both eyes, and all affected patients have shown some type of central or caeco-central scotoma. Interpretation of the appearance of the optic discs and maculae originally led to some difficulty, but experience gained by examination of fifty unselected West Indians in the out-patient eye department has clarified one or two points.

In this series there were ten patients who had defective vision in both eyes, central scotomata, and some degree of pallor of the optic discs.

\section{Summary of the Literature}

Defective vision with partial optic atrophy and central field defects has been reported in coloured people from most parts of the world. In the earliest papers on the subject nutritional deficiency was considered to be the basic cause, but recently Degazon (1956) in Jamaica has denied this and prefers to call the condition "tropical amblyopia". Behrman (1962) postulated that the condition was race-influenced and of genetic origin.

During the second world war, nutritional privations in prisoner-of-war and internment camps produced a similar condition in white people, giving the impression that the fairskinned person succumbs ultimately to a disease which occurs rather more readily in coloured races. There seems little doubt that nutritional deficiency and nutritional imbalance were the main causes of the amblyopia found in these prisoners; most writers agree that it was a deficiency of some component in the vitamin B complex, together with an excessive intake of certain carbohydrates. Many of the prisoners of war suffered from vitamin B complex deficiency symptoms, i.e. beri beri, scrotal dermatitis, stomatitis, and burning feet. It was also noticed in many camps that a large supply of carbohydrate in the diet provoked an earlier onset of retrobulbar neuritis. Psychological and constitutional factors were also thought to play some part and might influence the ultimate severity of the subjective defect.

Other writers have suggested that some toxin might be the cause, Scott (1918) incriminating sugar-cane tops, and Browne (1939) black pepper and ginger teas.

The problem to-day is to discover the cause of the amblyopia and partial optic atrophy seen in West Indian immigrants to the United Kingdom, and in particular those in south

\footnotetext{
* Received for publication May 20, 1965 .

$\dagger$ Part of a thesis accepted by Cambridge University for the degree of M.D. 
London. Is it a defect caused by past malnutrition? Is it hereditary, race-influenced, or constitutional? Is it due to some unknown toxin? Is it an early manifestation of one of the known neuropathic diseases like disseminated sclerosis or subacute combined degeneration of the cord, or is it due to living in the tropics? An attempt will be made here to answer these questions.

\section{Description of Cases}

The cases to be described were all seen in the ophthalmic department of King's College Hospital. When practicable all new West Indian patients referred to the department were examined by the author and assessed. Those with defective vision were investigated further and retinal photographs were taken of the optic discs and macular regions. Fifty cases were included in the series during the 12 months from February, 1963 to 1964 . Sixteen of these were found to have defective vision for which known causes could be found, such as glaucoma, trauma, and uncorrected refractive errors. Ten were found to have defective vision with pallor of the optic discs, central scotomata, and no other ocular signs. The remainder had normal or near normal vision.

Seven of these ten were men, out of a total of 33 men in the series, and three out of seventeen were women. Their ages ranged from 31 to 51 years (average 38). Six said that their vision had been bad since childhood and two for 10 to 15 years; two initially said that the onset was more recent, but later agreed that their sight had been poor for many years; it was felt that they were claiming a recent onset in an attempt to gain more attention.

The worst visual acuity was $1 / 18$ and the best $6 / 18$ (mean $6 / 24-6 / 36$ ).

The scotomata showed a variety of appearances. Nine eyes showed a central scotoma for a white test object with a larger defect for red (Fig. 1) and ten a defect for red only (Fig. 2). In one eye no field defect was demonstrated. In all cases the density of the scotoma was not as great as one would expect from the degree of defective acuity. This was thought to be partly due to poor concentration and fixation. The average West Indian is not an easy subject for scotometry and it may be necessary to repeat the test on a number of occasions and with a certain degree of rapidity.

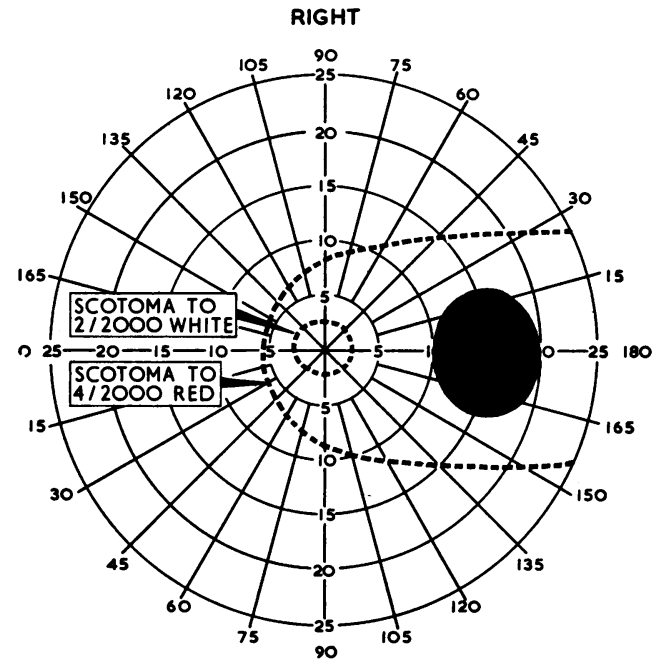

FIG. 1.-Right eye. Central scotoma for white test object with larger defect for red. Visual acuity $6 / 36$.

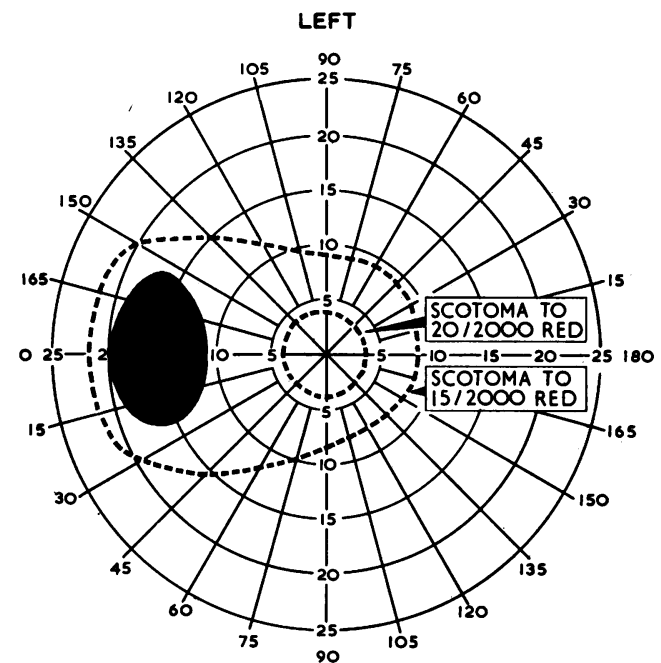

Fig. 2.-Left eye. Defect for red only. Visual acuity $6 / 60$.

The appearance of the optic discs must be interpreted in the light of the fact that the normal West Indian disc is much pinker than might be expected by comparison with the pigmented surrounding fundus, just as a negro's tongue appears to be unexpectedly pink by comparison with his pigmented skin. Where the optic disc is small the density of the pink colouring is enhanced (Fig. 3A); where the disc is large the density is decreased, but there is a rim of pink around the temporal edge of the disc (Fig. 3B). See colour plate opposite. 
A

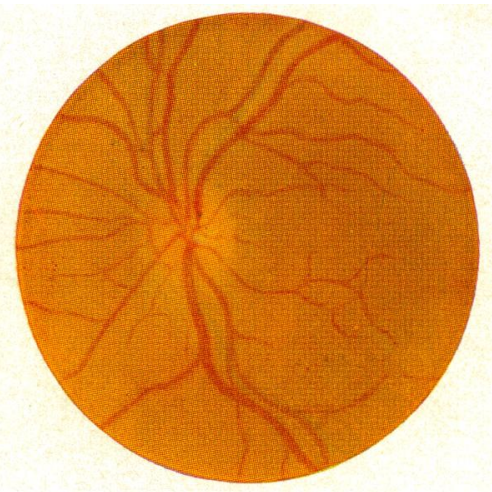

C

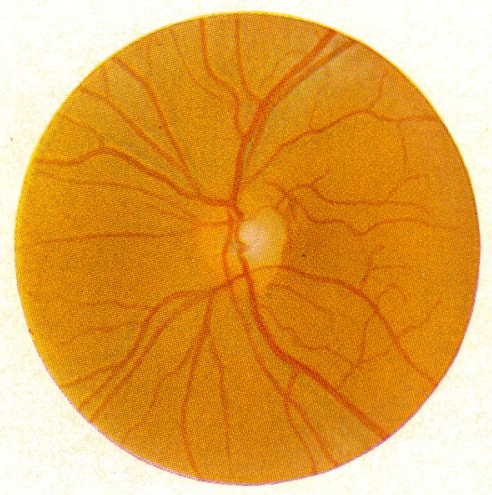

E

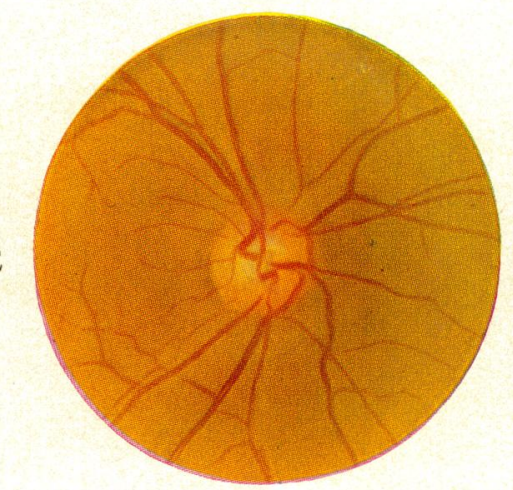

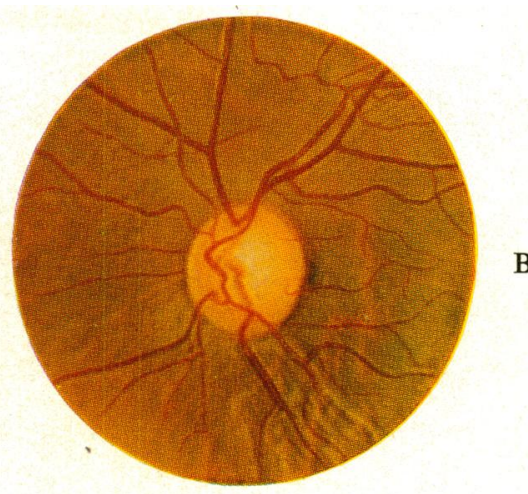

B

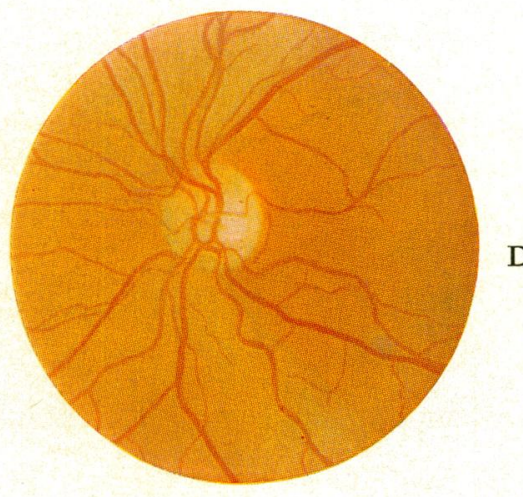

D

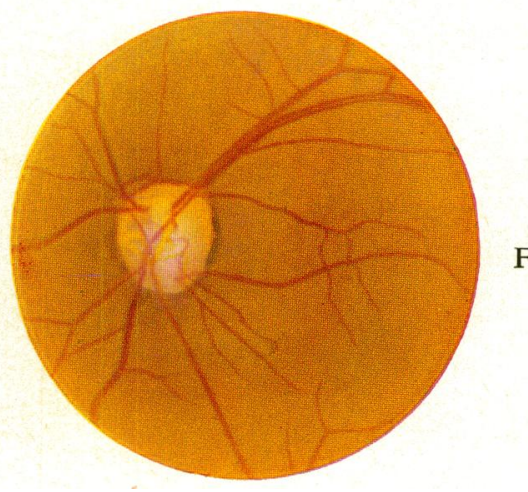

-

Fig. 3.-(A) Normal small optic disc, uniformly pink except for small central pit.

(B) Normal large optic disc, with narrow rim of colour around temporal margin.

(C) Small optic disc with temporal pallor. Visual acuity 6/36. Caeco-central scotoma to red.

(D) Large optic disc with temporal pallor. Visual acuity 6/60. Caeco-central scotoma to red.

(E) Normal optic disc. Right eye.

(F) Old traumatic optic atrophy. Left eye.

To face page 562 . 
Patients with defective vision and central scotomata all showed some degree of temporal pallor when judged by these criteria. The area and intensity of pallor depended not only on the severity of the visual defect, but also on the size of the optic disc (Fig. $3 \mathrm{C}, \mathrm{D}$ ). Optic atrophy secondary to trauma involving the optic nerve is differentiated as the whole disc is pale (Fig. $3 \mathrm{E}, \mathrm{F}$ ).

The maculae in the ten affected patients appear both clinically and photographically normal, and look the same as the maculae of patients with normal vision (Figs 4 and 5). The amount of pigment aggregated in the macular area varies and thus alters the ophthalmoscopic appearance; in particular the light reflection from the fovea is sometimes accentuated.

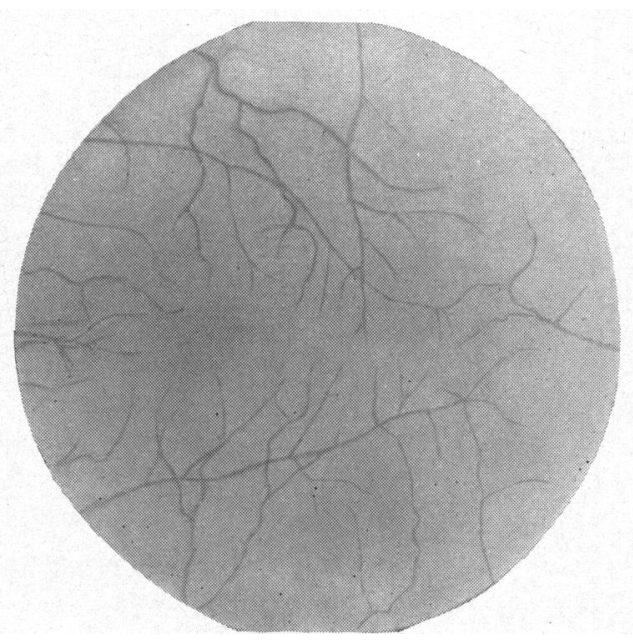

Fig. 4.-Normal macula. Visual acuity 6/6.

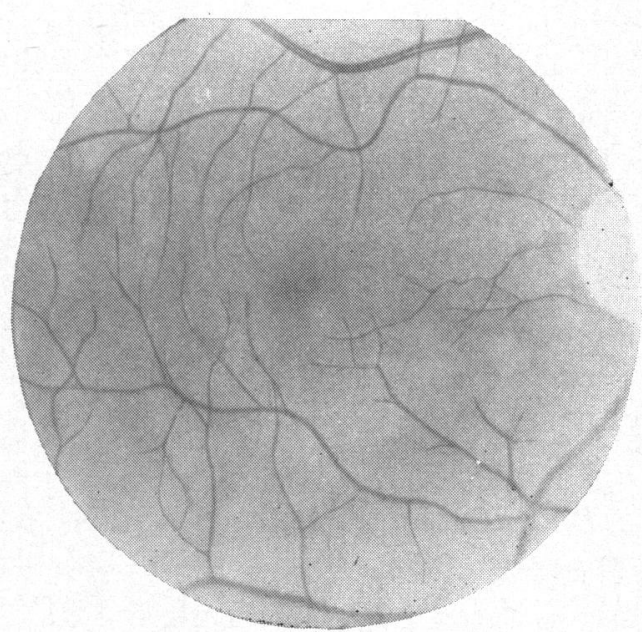

FIG. 5.-Normal macula with temporal pallor of optic disc. Visual acuity $6 / 36$.

The ten affected patients were given thorough medical and neurological examinations to exclude conditions such as disseminated sclerosis and chiasmal lesions. In addition a number of other investigations were carried out, for example, skull $x$ ray, blood Wassermann reaction, serum vitamin $\mathrm{B}_{12}$, lumbar puncture, azo dye test for gastric acidity, and xylose tolerance test for malabsorbtion. Nothing significant was found.

Various vitamin preparations were prescribed, including intramuscular vitamin $B_{12}$. Although the numbers were too small for a controlled therapeutic trial, it is worth recording that there was no improvement in visual acuity or field following vitamin therapy.

Two other patients are worth mentioning by way of differential diagnosis, both of whom appeared superficially to be affected cases. The first was a woman referred by the neurological department as a case of this type of optic atrophy. Her vision improved to 6/9 in each eye with the correct spectacle lenses, and her discs and fields were normal. The second was a man aged 63; he had $6 / 36$ visual acuity in each eye, apparently normal discs, and scattered drusen around the macular region. No field defect could be detected at the first attempt. When he was admitted for further investigation nothing abnormal was found, but a repeat perimetry showed a homonymous hemianopia. He had learnt to compensate for this by rapid movements of the eyes, and because his concentration and co-operation were not good it was extremely difficult to demonstrate the field defect.

\section{Discussion}

The problem of the aetiology of this optic atrophy continues to cause speculation. Non-nutritional causes have been eliminated by general examination, radiography, and blood and cerebrospinal fluid serology. A series of West Indian patients remains who show no signs of vitamin deficiency or of any significant neurological disease. The similarity between these cases and some of the prisoners of war 
previously mentioned is striking. For instance, in the series reported by Hobbs and Forbes (1946), there were 163 patients with partial optic atrophy, all of whom had been subjected to gross dietary deficiency. Of these, 53 gave no history of systemic signs of deficiency. The six cases quoted in detail and seen some time later showed only poor visual acuity, temporal pallor, and central field defects.

These are the same three signs as those shown by the affected patients in the present series. None of these West Indians reports any privation or dietary deficiency that he can remember. If there has been any nutritional deficiency it is likely to have occurred during childhood at an age when they would not have understood that they were being underfed or remember this as an incident many years later.

The reports by Browne (1939), Carroll (1944), and Whitbourne (1947) all relate to West Indians who were at school during the years 1934-39. They give evidence of nutritional deficiency in these children, many of whom eventually developed partial optic atrophy. It is likely that this deficiency has continued to affect West Indian children even since the period reviewed by these papers, and it probably existed before 1934. Cruickshank, Montgomery, and Spillane (1961) said that overt signs of malnutrition were still common in West Indian infants.

Rhodes (1957) examined 1,200 Jamaican children and reported a high incidence of malnutrition amongst them. Their diet consisted mainly of cereals and sweetened condensed milk. Infants up to 2 years old were seldom given foods rich in protein as the mothers considered them harmful. Children up to 12 years old also often subsisted on cornmeal porridge and condensed milk. Rhodes explained that these strange dietary habits resulted as much from ignorance as from poverty. There were no gross signs of vitamin deficiency in Rhodes' series, but there were occasional signs of lack of vitamins of the B group. Many of the children had veno-occlusive disease of the liver. There was no mention of any ocular involvement, but this does not prove the absence of defective vision as the children were examined only to determine the incidence of malnutrition and liver disease amongst them.

An unbalanced diet of the kind reported by Rhodes could well produce some degree of optic atrophy over a prolonged period. The children probably felt well fed, and would not consider, if questioned several years later, that their diet had been unbalanced or deficient.

In addition, during the early 1930s, a number of hurricanes affected Jamaica. A personal communication from the Weather Bureau, Miami, Florida, U.S.A., states that hurricanes or tropical disturbances affected the island on or about September 29, 1932, October 28, 1933, and September 27 and October 22, 1935. The last hurricane is listed as having caused damage amounting to two million dollars, mostly because of heavy rains. There was widespread damage to food crops, which presumably caused food shortages and aggravated malnutrition amongst the children.

These children would now be between the ages of 30 and 46 years, an age group embracing all but one of the affected cases in this series. It seems likely that some of them, now emigrants to Great Britain, are appearing in our hospitals, suffering from a condition which started in their infancy. 


\section{Response to Treatment}

Degazon (1956) reported a good response to a variety of vitamins and liver extracts. His results are much better than any quoted by the writers from the prisoner-of-war rehabilitation centres, although he makes the point that the most favourable feature was the shortness of history rather than the degree of visual defect. It is difficult to reconcile Degazon's results with the theory that this is a long-standing condition, arising in infancy, unless a great number of his patients appeared worse than in fact they were at their first visit, and subsequently "improved" on treatment. One patient in our present series complained of poor vision, but there was no temporal pallor, nor could any field defect be demonstrated. Subsequently the visual acuity improved spontaneously from $6 / 18$ to $6 / 9$ without any treatment. Had she been given some vitamin preparation the improvement might well have been attributed to it, instead of which there is little doubt that her vision was "normal" at her first visit, although it appeared to be defective. Degazon performed field tests on only 98 of his 289 cases, but he found central defects in 81 of these. Some of those with central defects improved on his treatment, the scotoma becoming smaller.

Neither of the two cases quoted in detail by Degazon compares with any of those in the present series. It is possible that he is describing a different condition, or a number of different conditions. All the affected cases in this series have the triad of signs: defective visual acuity, central field defects, and temporal pallor of the optic discs. Not all Degazon's cases had field defects and only 50 per cent. showed temporal pallor.

Prisoners of war with marked pallor of the disc of more than 3 years' duration could not be expected to improve even with treatment (Ridley, 1946). The fact that none of the affected patients in this series has improved on vitamin therapy supports the theory that they are suffering from a long-standing condition.

\section{Differential Diagnosis}

Other possible causes of bilateral optic atrophy must be considered.

\section{Syphilis}

Habib (1962) discussed the cases of 31 West Indians with proven or likely neurosyphilis. Only four of these had optic atrophy, two in association with other forms of neurosyphilis, and two with absent knee- and ankle-jerks as the only other clinical neurological sign. All had positive serological findings in blood and cerebrospinal fluid. No case of acute retrobulbar neuritis was attributed to syphilis. Loss of vision was gradual, progressive, bilateral, and severe. In one patient, vision was reduced to perception of light in one eye and no perception of light in the other. In another the visual acuity was $6 / 60$ in each eye and there were large central scotomata extending outwards to the periphery, leaving only small islands of vision in the inferior quadrants. He concluded that optic atrophy without other signs was uncommon in syphilis.

None of the cases described in this series had such severe loss of vision and extensive field defects combined. In addition, none had any neurological signs such as absent ankle- or knee-jerks. One patient had a positive Wassermann reaction which was considered to be due to syphilis, but had no neurological signs of this 
disease; another had a positive Wassermann reaction which on detailed serological examination was considered to be due to yaws.

\section{Pernicous Anaemia}

Amblyopia is very infrequently seen as a presenting symptom in pernicious anaemia without some other signs in the blood or central nervous system. No such signs were found among the affected patients in this series except for one case with achlorhydria. Cruickshank (1956) found histamine-fast achlorhydria in 25 out of ninety cases of neuropathic syndrome under investigation. He did not have figures for a similar group of the population without a neurological disorder and thought it might indicate defective digestion and absorption.

Vitamin $B_{12}$ serum estimations were done in eight of the ten affected patients and in two of the normal West Indians in this series. The range for the affected patients was 350 to $600 \mu \mu \mathrm{g}$. per ml. (average 430), well above the critical level of $250 \mu \mu \mathrm{g}$. per ml. mentioned by Heaton, McCormick, and Freeman (1958). The range for the two normal cases was 400 to $700 \mu \mu \mathrm{g}$. per ml. (average 550).

It is concluded that neither pernicious anaemia nor vitamin $\mathbf{B}_{12}$ deficiency was the cause of the optic atrophy found in these West Indians.

\section{Tobacco-Alcohol Amblyopia}

The scotoma found in all the affected West Indians is not typical of that usually described in cases of tobacco-alcohol amblyopia. In this condition islands of scotoma lie between the fixation and blind spots, and there is a large surrounding area in the temporal field of relative scotoma for red objects. Alternatively there may be a central scotoma which tends to elongate towards the blind spot; the blind spot may also elongate nasally and the two fuse into one long "sausage-shaped" caeco-central scotoma. The scotomata found in these West Indians do not have any horizontal elongation of either the blind spot or the central nucleus, but the defect for red does tend to be caeco-central and spreads to the temporal side, suggesting some papillo-macular bundle involvement.

Several of the West Indians in the affected series did not smoke at all, and those that did said that they were not heavy smokers. None of them admitted to being heavy drinkers, most stating that they only drank alcohol occasionally for social purposes. Tobacco-alcohol amblyopia as an entity is therefore eliminated as a cause of the amblyopia in these West Indians.

\section{Disseminated Sclerosis}

This condition sometimes presents as acute retrobulbar neuritis which may be bilateral. Temporal pallor of both discs is often a residual sign, but the visual functions may be unimpaired, visual acuity and central fields returning to normal. As the disease progresses other neurological signs become apparent and these signs show progression and regression. None of these features was found in this series. In addition multiple sclerosis is rare in the negro population (Cruickshank, 1956).

\section{Pressure or Traumatic Optic Atrophy}

This is a diagnosis which must be excluded in all cases. Skull radiography, visual fields, and general examination to exclude local neurological signs or signs of 
pituitary dysfunction, should help to make the diagnosis. Chiasmal compression usually produces definite field changes by the time the visual acuity has dropped to $6 / 18$ and pallor of the optic disc has appeared. There are many variants of the type of field defects possible in chiasmal lesions, but the commonest is a bitemporal defect, in the early stages perhaps only to a small red object.

A lesion of one optic tract will ultimately produce a marked pallor of one disc and temporal pallor of the other. This might be confused with the optic atrophy seen in this series. The visual field, however, would show a hemianopia to the side with the more marked pallor.

Unilateral pallor of one disc due to trauma to the optic nerve is diagnosed from a study of the history, and by comparing the two optic discs (see Fig. 3, E, F).

\section{Race-influenced and Familial Optic Atrophy}

Behrman (1962) considers that the optic atrophy seen in 17 West Indian immigrants is race-influenced. The genetic transference suggested by Behrman would produce a family history in which one in sixteen of the offspring would be affected. He rightly says that this would be a difficult family history to follow up, owing to the low frequency of occurrence, and would certainly not be apparent on routine questioning of immigrants. Whole families would have to be followed up to obtain any evidence of such a connexion. These families are now split up, and immigrants appearing in England represent small parts of families. Nevertheless, none of the affected cases in this series gives any history of relatives with defective vision. Too much importance should not, however, be attached to their evidence. Degazon (1956) does not mention the possibility of genetic transference in his review of 289 cases of amblyopia from Kingston, Jamaica. A familial incidence of one in sixteen might be expected to show itself in such a series drawn from a local area over a period of seven years. If there is any race influence it is likely to be a tendency of the negro to succumb more readily than the white man to nutritional deficiencies.

\section{Toxic Amblyopias}

The drinking of bush teas is common practice in the West Indies, and some of the immigrants still have bush sent over here from their homeland so that they can continue the practice. One patient had been drinking bush tea daily for forty years and continues to drink it. His vision was $6 / 6$ in each eye and there was no evidence of optic atrophy. This does not eliminate bush teas as a possible source of toxin. Asprey and Thornton $(1953,1954,1955)$ review over 160 plants used in the West Indies for medicinal purposes. Many of them are used as remedies for numerous common complaints and some are supposed to have aphrodisiac qualities. Perhaps this accounts for the rather sheepish smiles which usually answered the question "Do you drink bush tea?" Asprey and Thornton list the various actions of the plants reviewed and do not mention that any of them are known to cause optic atrophy.

Of the West Indians included in this series, 37 admit to having drunk bush teas at some time in their lives. Of the 10 affected patients, 9 admit to drinking bush tea occasionally, and of the 40 unaffected cases 28 admit to drinking bush teas, many of 
them daily for years. It does not seem possible that this can be the prime factor, but if the teas are mildly toxic thay may have some detrimental action on an optic nerve weakened by nutritional deficiency. There must be some additional cause for amblyopia in affected patients who say that they have never drunk bush tea.

\section{Other Causes}

Solar radiation, heavy labour, and emotional strain are quoted as other possible causes in a review by Leigh (1948). He concluded that any of these may be a contributing factor in an individual case, but that none of them seemed to be the essential factor.

\section{Conclusion}

It is concluded that the condition described is due to nutritional deficiency in childhood for the following reasons:

(1) The condition appears to be static, and does not respond to treatment with vitamins.

(2) Eight out of the ten affected patients said that their eyesight had been bad for many years.

(3) There is evidence from the West Indies that many children and infants have been, and continue to be, incorrectly fed.

(4) School-children in the West Indies have been shown to have optic atrophy and defective vision due to malnutrition, which was reversible only if discovered and treated early.

(5) A similar condition was found amongst prisoners of war during the second world war, and was shown to be due to malnutrition.

\section{Summary}

(1) When 50 West Indian immigrants were studied, 10 were found to have a triad of signs: (a) defective vision, (b) pallor of the temporal half of both optic discs, and (c) central field defects, mainly for red objects.

(2) General examination and investigation of such patients as submitted themselves failed to show any evidence suggesting that the ocular signs were part of a general neurological condition such as disseminated sclerosis, syphilis, or subacute combined degeneration of the cord.

(3) The possibility of a toxin in bush teas has been considered, but there is no evidence to support this.

(4) A study of the literature shows that many West Indian children suffer from gross nutritional deficiency during the first few years of life, and there is evidence to show that many school-children have optic atrophy and defective vision. Some probably regain normal vision while others are left with defective vision and a central scotoma. With an improved nutritional state an absolute scotoma for a white target would become relative for red.

(5) Comparison with a similar condition found in ex-prisoners of war known to have suffered severe nutritional deficiency leads to the conclusion that the condition described in these West Indian immigrants is due to nutritional deficiency in childhood. 
I wish to thank Mr. L. H. Savin, Mr. T. Keith Lyle, and Mr. R. Pitts-Crick for their help, and for permission to report their cases; and all other staff who helped in any way, in particular the staff of the Pathology Laboratories and Radiological Department of King's College Hospital. I am grateful to the Research Committee of King's College Hospital for a grant towards the cost of the coloured illustrations.

\section{REFERENCES}

Asprey, G. F., and Thornton, P. (1953). West Indian med. J., 2, 233.

- (1954). Ibid., 3, 17.

(1955). Ibid., 4, 69, 145.

BeHRMAN, S. (1962). Brit. J. Ophthal., 46, 554.

Browne, J. A. (1939). Carib. med. J., 1, 218.

CARroll, F. D. (1944). Amer. J. Ophthal., 27, 713, 847.

Cruickshank, E. K. (1956). West Indian med. J., 5, 147.

, Montgomery, R. D., and Spillane, J. D. (1961). Wld Neurol., 2, 199.

Degazon, D. W. (1956). West Indian med. J., 5, 223

HABIB, G. B. (1962). Ibid., 11, 100.

heaton, J. M., McCormick, A. J. A., and Freeman, A. G. (1958). Lancet, 2, 286.

HobBs, H. E., and Forbes, F. A. (1946). Ibid., 2, 149.

LeIGH, A. G. (1948). Ophthal. Lit., 2, 53, 163.

RHODES, K. (1957). West Indian med. J., 6, 1.

RIDLEY, H. (1946). Trans. ophthal. Soc. U.K., 66, 45.

ScotT, H. H. (1918). Ann. trop. Med. Parasit., 12, 109.

Whitbourne, D. (1947). Amer. J. Ophthal., 30, 169. 